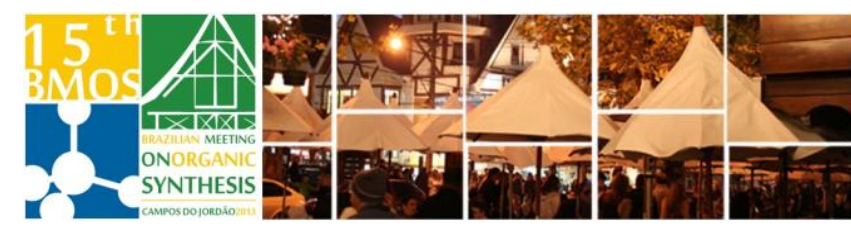

\title{
A New Approach to Atropisomerism
}

\section{Flávio Sêga Pereira Cardoso and Aaron Aponick*}

University of Florida, Department of Chemistry, P.O. Box 117200, Gainesville, FL, USA

\section{*aponick@chem.ufl.edu}

Keywords: biaryl, $\pi$ - $\pi$ stacking, asymmetric catalysis

\section{INTRODUCTION}

The design of new chiral ligands is on the cutting-edge of organic synthesis. In particular, the field of atropisomeric ligands has shown to be very successful in asymmetric catalysis, ${ }^{1}$ however, the majority of axially chiral biaryl ligands are comprised of six-membered aromatic rings. In this context, creative new atropisomeric ligand scaffolds should advance the field by using other ring sizes. Herein, a novel strategy towards the design of a new family of ligands, which will allow the synthesis of atropisomeric ligands containing a five membered ring in the biaryl backbone is described. We aim to design a new system in which the barrier to rotation of a biaryl bond is increased due to the decrease of the groundstate energy of enantioconfomers. In general, the presence of sterically demanding groups ortho to the atropisomeric axis are employed to increase the barrier to rotation (Figure 1, A), but surprisingly the simple concept of groundstate stabilization proposed herein has not been explored (Figure 1, B).

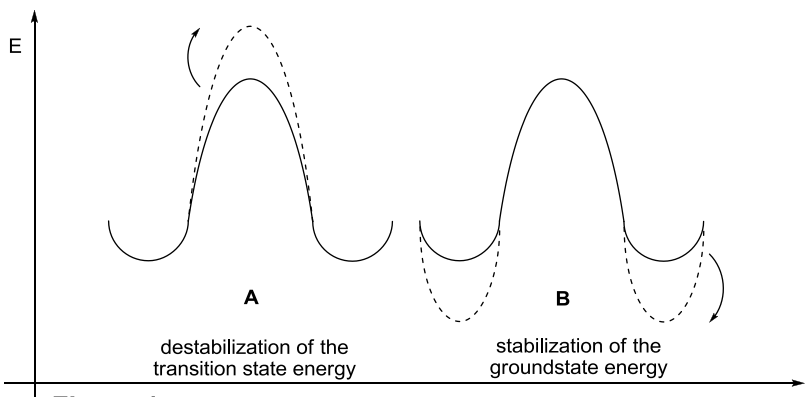

Figure 1. Energy diagram for the new class of atropisomers.

Our model system is a biaryl structure composed of three aromatic units A, B and C designed to $\pi-\pi$ stack $^{2}$ intramolecularly (Figure 2 ).

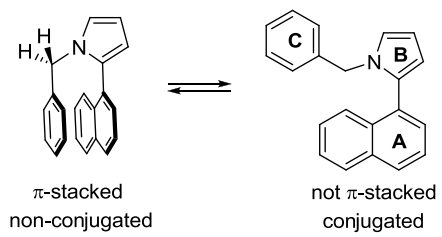

Figure 2. Proposed model

This system presents two main advantages: 1) the easy calculation of the biaryl bond barrier to rotation using VT-NMR (diastereotopic methylene protons); 2) easily modified $A / B$ rings to the preparations of functional molecules.

\section{RESULTS AND DISCUSSION}

A variety of compounds were synthesized in order to understand the factors that control the intramolecular $\pi-\pi$ stacking (Figure 3 ). It was observed that different nature of rings $A, B$ and $C$ can affect significantly the barrier to rotation of the biaryl bond.

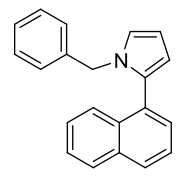

$\Delta \mathrm{G}^{\ddagger}=13.9 \mathrm{kcal} / \mathrm{m}$

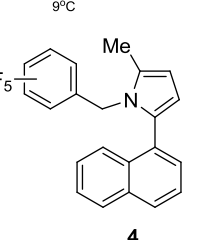

4

$\Delta \mathrm{G}_{62^{\circ} \mathrm{C}}^{\ddagger}=16.7 \mathrm{kcal} / \mathrm{mol}$

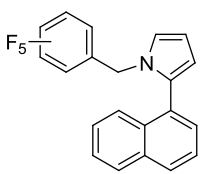

2

$\Delta \mathrm{G}_{57^{\circ} \mathrm{C}}^{\ddagger}=16.3 \mathrm{kcal} / \mathrm{mol}$

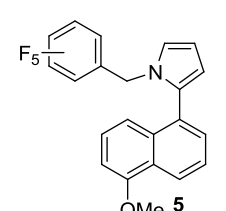

OMe 5

$\Delta \mathrm{G}_{61^{\circ} \mathrm{C}}^{\ddagger}=16.5 \mathrm{kcal} / \mathrm{mo}$
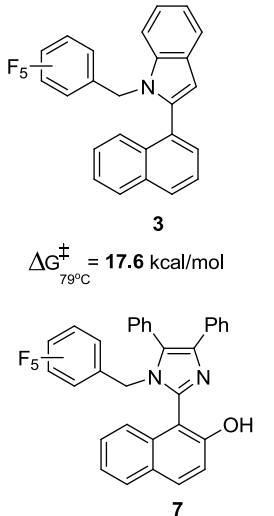

$\Delta \mathrm{G}^{\ddagger}>\mathbf{2 0} \mathrm{kcal} / \mathrm{mol}$
Figure 3. Selected examples of the compounds.

\section{CONCLUSION}

The concept of stabilizing enantioconformers was demonstrated using a biaryl system capable of intramolecular $\pi-\pi$ stacking interactions. The system is currently being applied in the design of a new family of chiral ligands containing biaryls comprised of five- and six-membered aromatic rings and with easily incorporated and tunable structural features. These results will be presented on the poster.

\section{ACKNOWLEDGEMENTS}

The authors thank the University of Florida for their generous support of our programs.

\section{REFERENCES}

1. Yoon, T. P.; Jacobsen, E. N. Science 2003, 299, 1691-1693.

2. (a) Meyer, E. A.; Castellano, R. K.; Diederich, F. Angew. Chem., Int. Ed. 2003, 42, 1210-1250. (b) Salonen, L. M.; Ellermann, M.; Diederich, F. Angew. Chem., Int. Ed. 2011, 50, 4808-4842. 